\title{
EXCISION OF SACCULAR ANEURYSMS OF THE THORACIC AORTA: A REPORT OF FIVE CASES \\ BY
}

\author{
B. J. BICKFORD AND J. S. GLENNIE
}

From the Department of Thoracic Surgery, University of Liverpool, and the Liverpool Regional Thoracic Surgical Centre, Broadgreen Hospital, and the Department of Thoracic Surgery, Victoria Hospital, Blackpool

(RECEIVED FOR PUBLICATION JULY 5, 1960)

The history of the surgery of aortic aneurysm is long, yet it is only in recent years that any progress has been made. Some landmarks may be noted. In 1864, Moore and Murchison described the method of intrasaccular wiring of an abdominal aortic aneurysm which was unsuccessful in this case because of infection introduced at the same time. This method was modified by Blakemore and King (1938), who used an electric current to promote clotting by heating the wire, and by Linton (1952), who stressed the need to insert a sufficient length of wire ; Colt (1925) also modified this technique by introducing his umbrella-like wire "wisp." Meanwhile Poppe and de Oliviera (1946) had discovered that polythene film produced with the aid of a chemical solvent (dicetyl phosphate) produced a dense fibrosis around the wall of a saccular aneurysm, and some good results from this method of treatment were reported. In this country Borrie and Griffin (1950) described a series of cases of aortic aneurysm, nine of which were treated by Colt's wire wisp. Only five patients were alive at the time of the report, 12 to 32 months after the operation. Two cases treated by cellophane wrapping died from causes unrelated to the aneurysm. Borrie and Griffin considered that saccular aneurysms were likely to be helped by promotion of intrasaccular clotting. One of us (Bickford, 1956) reported the results of surgical treatment of eight cases of aortic aneurysm. Five were treated by wrapping with reactive polythene without demonstrable improvement, one by a Colt's wire wisp, and three (including one of the polythene-wrapped cases) by insertion of long lengths of stainless steel wire into the sac. Only one of these patients, who had 48 yards of wire inserted into a large saccular aneurysm in July, 1953 , is alive at the present time. She improved symptomatically and has shown no subsequent deterioration. The results of such indirect operations were uncertain, and, on the whole, disappointing.

\section{The Radical Appronch}

It had been known for a long time that saccular aneurysms of the aorta were frequently due to the massive enlargement of a relatively small area of weakness in the wall of the syphilitic aorta, often a "split" in the medial coat only a few centimetres long. Excision of the sac, after clamping its base, therefore appeared to be a reasonable approach to the surgical problem. This radical and logical approach was foreshadowed by the great French surgeon Tuffier in 1902, when he proposed to suture the base of a saccular aneurysm of the ascending aorta. He abandoned this plan in favour of ligating the sac of the aneurysm, and it is unfortunate that this resulted in death from a secondary haemorrhage, presumably from infection in the sac. Rénon (1921) reported a second case operated on by Tuffier in which the wall of a fusiform aneurysm of the ascending aorta was reinforced by strips of fascia lata encircling it. The patient was a woman aged 62 who survived for six and a half years, and died of a carcinoma of the uterus. A post-mortem examination could not be made, but there was symptomatic improvement and some radiological evidence of decrease in size of the aneurysm.

Ochsner $(1944,1952)$ excised and sutured the base of a small saccular aneurysm of the descending aorta which had been encountered unexpectedly during an operation for a supposed mediastinal tumour. This operation was a complete success, and was the basis for further advances.

In the same year Alexander and Byron (1944) reported the successful excision of a saccular aneurysm of the descending aorta. The aneurysm probably arose at the site of a coarctation : $7.5 \mathrm{~cm}$. of the aorta was removed with the aneurysm, and as the collateral circulation was well developed no attempt was made to restore the continuity of the aorta. The patient, a young man, survived for two 
years after the operation. His blood pressure was considerably elevated after the operation, and he died as a result of a series of cerebral vascular accidents.

Meyer, Monod, Brunel, Nico, and Dubois de Montreynaud (1948) reported the successful excision of a non-syphilitic saccular aneurysm of the terminal portion of the aortic arch. The diagnosis of aneurysm had not been confidently made before operation. The suture line was $4 \mathrm{~cm}$. in length, and there was no reduction in the lumen of the aorta as a result.

Cooley and DeBakey (1952), in a paper that has become a classic, reported two cases in which aneurysms were successfully treated by excision and lateral suture of the aorta. One patient, in whom the innominate artery was involved, survived, but the second died after excision of a saccular aneurysm of the ascending aorta. A bilateral trans-sternal thoracotomy was used, and death seemed to be due to diffuse cerebral damage because of inadequate ventilation during operation.

Bahnson (1953) reported eight cases in which saccular aortic aneurysms were excised; six were successful, two died.

In this country Rob (1954) and Sellors (1956) have described successful operations for aortic aneurysms associated with coarctation of the aorta.

Cooley, DeBakey, and Creech (1957) reported the surgical treatment of 313 aneurysms of the aorta. The majority of these were abdominal. There were 24 cases of saccular aneurysms of the arch of the aorta, with nine deaths. Fifteen of these arose in the ascending aorta, and the mortality among these (seven) was almost $50 \%$. Fiftynine aneurysms arose in other portions of the thoracic aorta. The major cause of death in all these cases was cardiac failure, the next commonest being cerebral thrombosis. Forty-three of the aneurysms of the thoracic aorta were fusiform and 16 were of the dissecting type.

Whereas a saccular aneurysm presents a reasonably easy problem of surgical technique, the fusiform aneurysm is a much more difficult one. The only way in which complete relief can be obtained is by excision of the whole abnormal segment of the aorta and replacement by a graft or prosthesis, a formidable task when the great branches of the arch are involved. The principles and practice of this type of replacement of the aorta and its branches have been set forth with clarity and ingenuity by DeBakey (1959), whose experience in this field is unrivalled.

The long-term survival of aortic grafts is not yet known, but the immediate results are reason- ably good; more time must elapse before a final judgment can be made.

\section{CASE RePorts}

Our personal experience of the excision of saccular aortic aneurysms is of five cases, the first of which was operated on in 1955. Details of our operative experiences are as follows:

Case 1.-E.P., a Polish man, aged 51, presented with a history of dyspnoea and stridor, particularly when lying down. On examination there was no abnormality to be found apart from distended neck veins and prominent veins on the chest, suggesting obstruction of the superior vena cava. A radiograph (Fig. 1) showed an opacity in the upper mediastinum which was thought to be due to a tumour, possibly a retrosternal thyroid, though the diagnosis of aortic aneurysm had been considered. At operation (J. S. G.) in June, 1955, a low cervical incision was made and the thyroid explored. This was found to be normal, and the tumour was coming up from the mediastinum. The sternum was split vertically and the mass readily dissected out, although it was firmly adherent to the right innominate vein which was damaged and required suturing. It was a saccular aneurysm arising from the arch of the aorta. The whole aneurysm was excised and a communication with the aorta lay between the origins of the left subclavian artery and the left common carotid, not more than $1 \frac{1}{2} \mathrm{~cm}$. in length. It was sutured by interrupted No. 60 linen thread. He made an uninterrupted recovery (Fig. 2). The Wassermann reaction was negative.

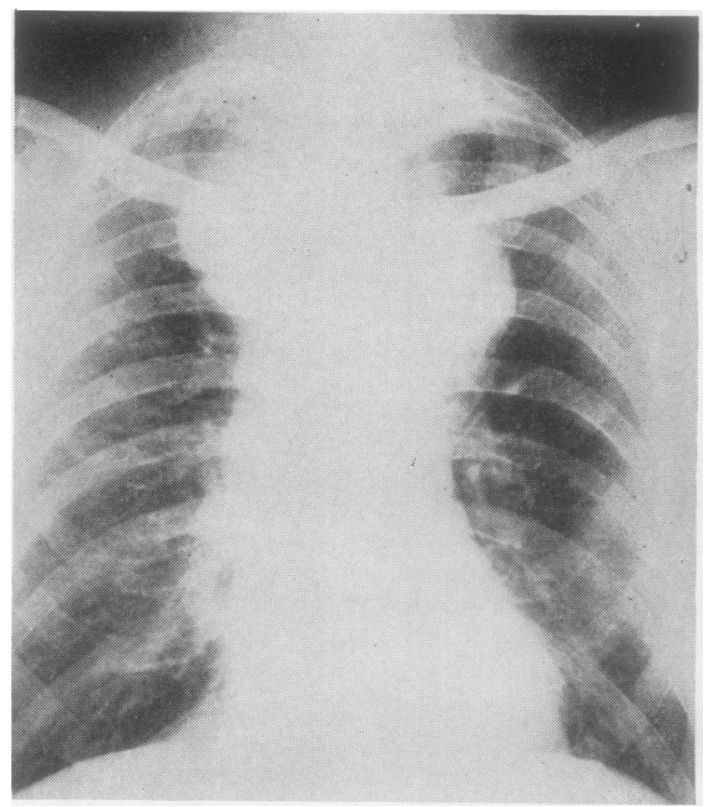

Fig. 1.-Case 1: Pre-operative postero-anterior radiograph of the chest. 


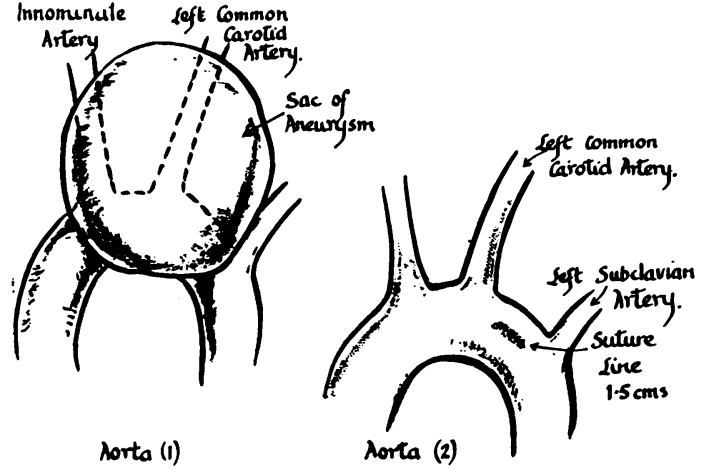

FIG. 2.-Case 1: Operation findings.

The patient has since emigrated to Canada, and was well in December, 1959, four and a half years after the operation.

CASE 2.-Mrs. E. T., a woman of 46 with a history of seven months' cough and dyspnoea on exertion, was referred for surgical consultation by Dr. W. Sutton in July, 1958. There was expansile pulsation in the left parasternal region, and it was thought that this was becoming more evident, as it was not observed to be present on her first attendance at the out-patient clinic. A radiograph (Fig. 3) showed a large opacity to the left of the mid-line. The transverse and descending portions of the aortic arch could be seen to be separate from the mass in lateral (Fig. 4) and oblique views, and because there was no paralysis of the left recurrent laryngeal nerve it was thought to be a saccular aneurysm arising from the left side of the ascending part of the aortic arch, and that it might be possible to resect the sac. There was no evidence

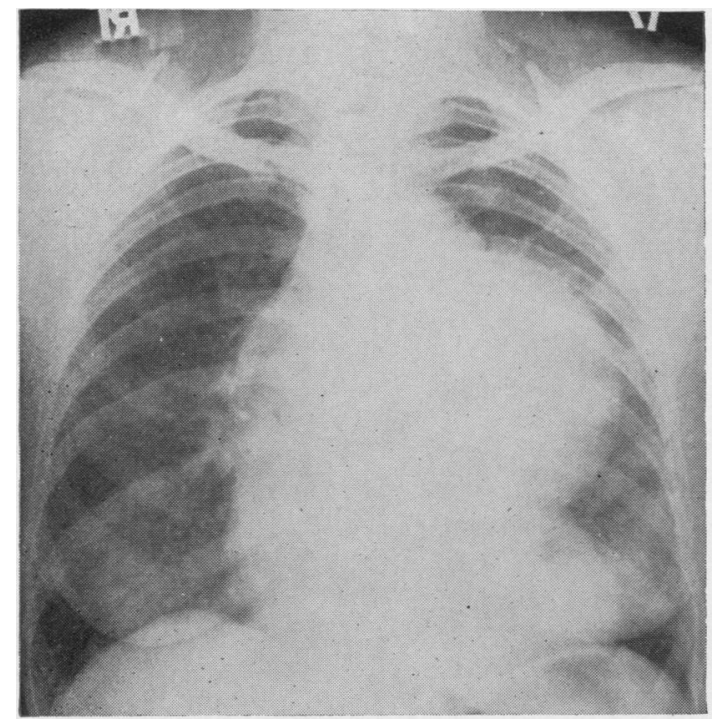

Fio. 3.-Case 2: Pre-operative postero-anterior radiograph showing large saccular aneurysm of the arch of the aorta.

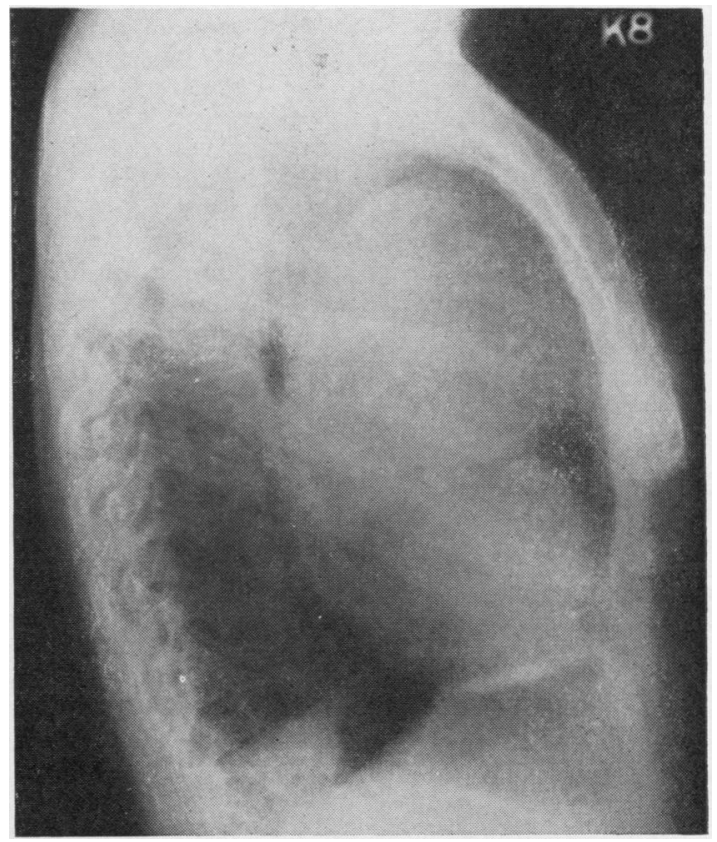

FIG. 4.-Case 2: Lateral radiograph of the chest.

of aortic valve disease, but the Wassermann reaction was strongly positive. An aspirating needle withdrew blood at a depth of $4 \mathrm{~cm}$., suggesting that the wall of the aneurysm was a thick one. At operation, on July 25, 1958 (B. J. B.), a bilateral trans-sternal thoracotomy was made and it was possible to place strong clamps across the base of the sac and to excise it without undue difficulty. The wall of the aorta, though diseased, patchily calcified, and atheromatous, proved to be much thickened, and held sutures well. The suture line was $8 \mathrm{~cm}$. in length (Fig. 5). Being

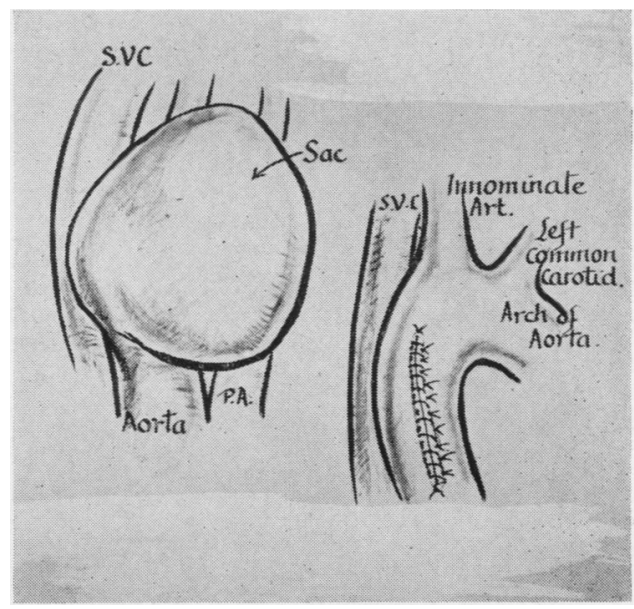

FIG. 5.-Case 2: Operation findings. 
uncertain whether the sutured aortic wall would be stronger than the rest of aorta it was thought wise to wrap it as well as possible in a jacket of nylon cloth. This had the additional advantage of appearing to reinforce several areas of weakness in the wall of the aorta lower down in the ascending portion. Apart from transitory cerebral symptoms (probably due to a Herxheimer reaction because the beginning of antisyphilitic treatment coincided with the operation), she made a good recovery. She is well 18 months after the operation. The radiograph still shows an enlarged aortic arch (Fig. 6), but it has not altered under observation. The suture line stood up to the strain of the patient falling downstairs at home during her early convalescence. Fig. 7 shows the excised aneurysmal sac.

CASE 3.-R.S., a man, aged 45 , had been operated on five years previously for a suspected bronchial carcinoma (Fig. 8). He was found at operation to have a saccular aneurysm of the ascending aorta and surgical treatment was not feasible at that time. The Wassermann reaction was strongly positive. During the next five years he continued to have pains in the chest, and, although adequately treated for syphilis, the aneurysm increased markedly in size. Mr. F. Ronald Edwards kindly referred the patient to one of us (B. J. B.) and surgical treatment was decided upon. There was by this time clinical evidence of mild aortic incompetence, with a blood pressure of $130 / 70 \mathrm{~mm}$. $\mathrm{Hg}$ and no cardiac enlargement (Fig. 9).

At operation (B. J. B.) on June 12, 1959, a bilateral trans-sternal thoracotomy was made and a very large thin-walled saccular aneurysm of the ascending aorta was discovered. Being densely adherent to the right

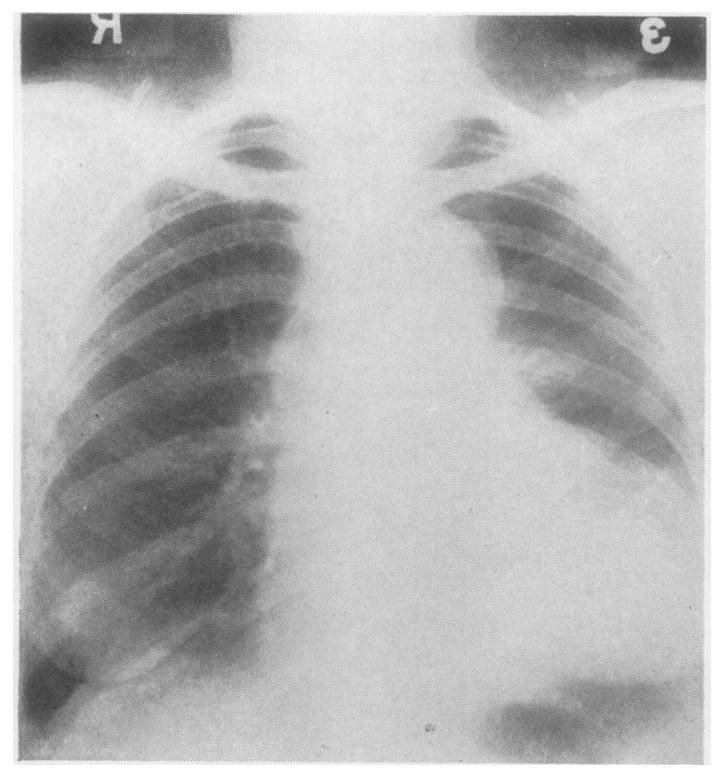

Fig. 6.-Case 2: Postero-anterior radiograph of the chest 10 months after operation.
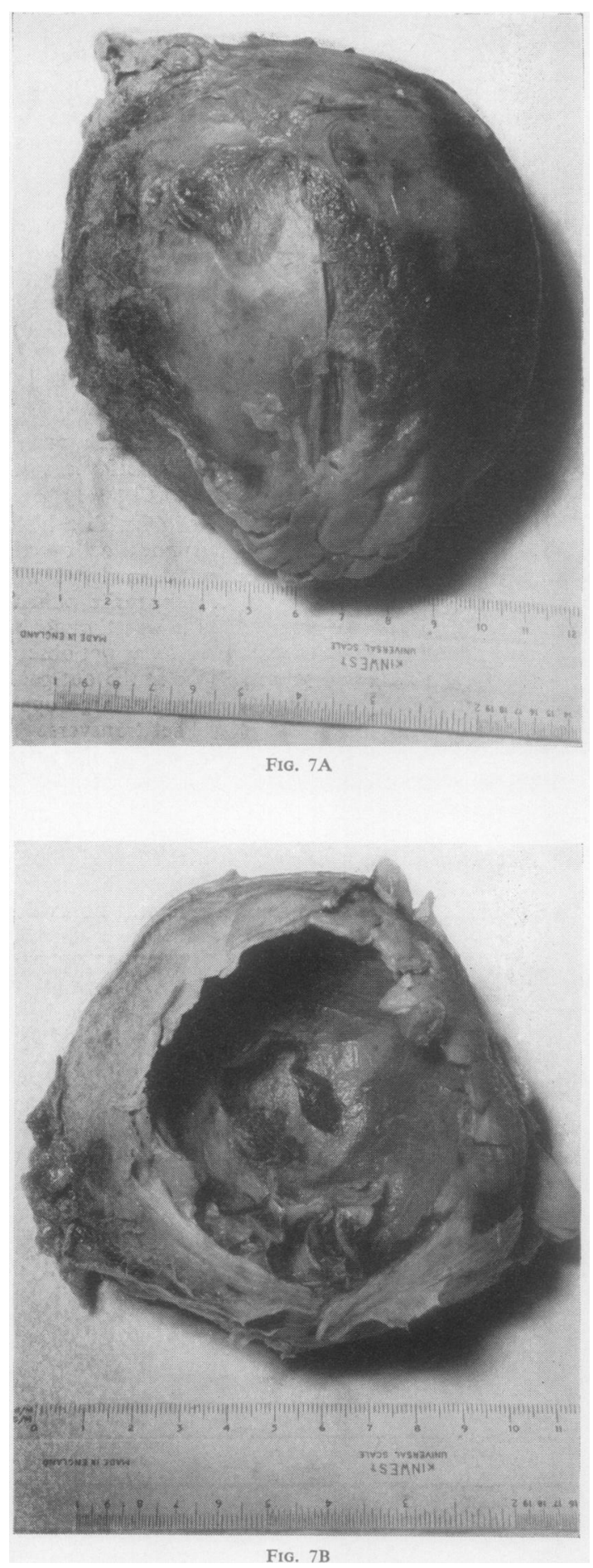

Fig. 7A and B.-Case 2: The excised aneurysmal sac. 
lung and to the superior vena cava, it was difficult to dissect out: it was eventually freed completely, though not without some excitement through an injury to the right pulmonary artery behind the aorta. Because of anxiety about the extreme thinness of the sac a combination of hypothermia (to $33^{\circ}$ C.) with

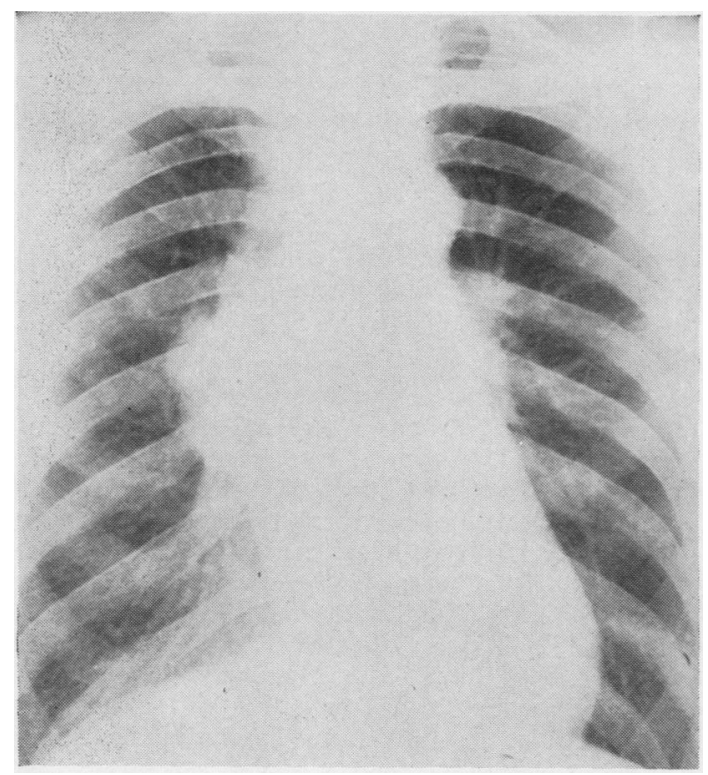

Fig. 8.-Case 3: Radiograph of the chest (1953).

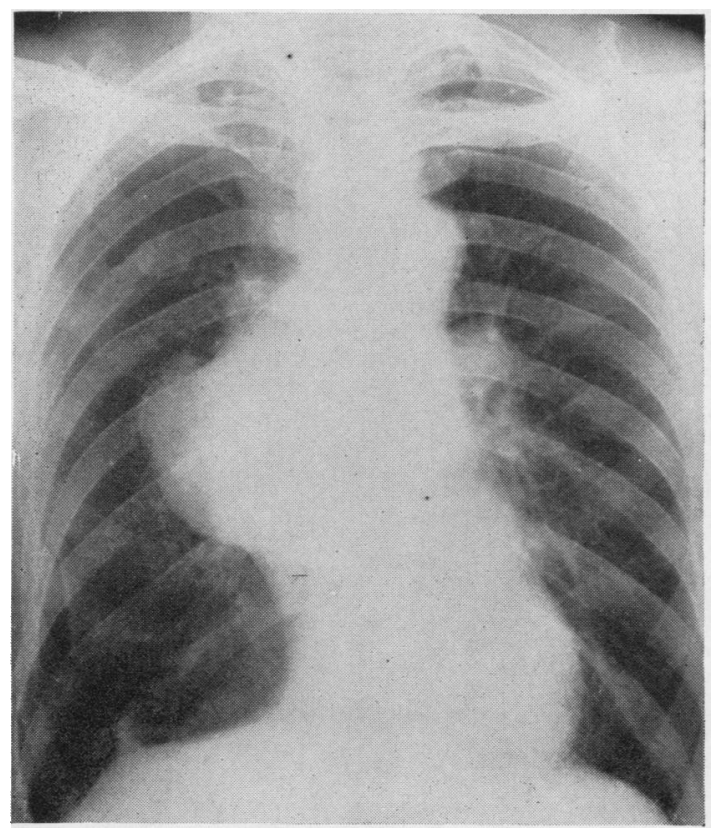

Fig. 9.-Case 3: Pre-operative radiograph of the chest (1959). "arfonad" hypotension was used at this stage, and this made clamping the base of the sac much easier. The suture line was $10 \mathrm{~cm}$. in length, and, although the aortic wall held the sutures well, patches of calcification impeded passage of the needle at many points. A small "ivalon" patch had to be sewn over one leaky area before haemostasis was satisfactory. Because of a second smaller saccular area, which did not seem to be amenable to excision, a reinforcing quadruple layer of nylon cloth was wrapped round the whole circumference of the aorta (Fig. 10).

The immediate convalescence was marked by a mildly hypotensive state (blood pressure $90 / 50 \mathrm{~mm}$. $\mathrm{Hg}$ ). The general condition was good until the second post-operative day, when jaundice and oliguria were evident. The jaundice became profound and was followed by anuria and coma, death taking place about 70 hours after the operation, apparently from hepatic and renal failure.

Shortly before death the serum bilirubin level was $11.2 \mathrm{mg} . / 100 \mathrm{ml}$. ; Na, $129 \mathrm{mEq}$./litre ; K, $8.7 \mathrm{mEq} . /$ litre; $\mathrm{Cl}, 85 \mathrm{mEq}$./litre. The blood urea was 186 $\mathrm{mg} . / 100 \mathrm{ml}$.

Pathological Findings.-Necropsy revealed an incompetent and calcified aortic valve. The aortic suture line was intact, but the wall of the aorta itself was much damaged by syphilitic aortitis.

The heart and the descending aorta were normal. The liver was small, 1,300 g. in weight, and yellow and tough in consistency. The kidneys showed pale wide cortices and congestion of the medullae. There were a number of cortical haemorrhages in the brain and some early softening of the left cerebral cortex. Histological examination of the liver showed bile retention in the liver columns and oedema of liver cells near the biliary tracts indicative of early toxic

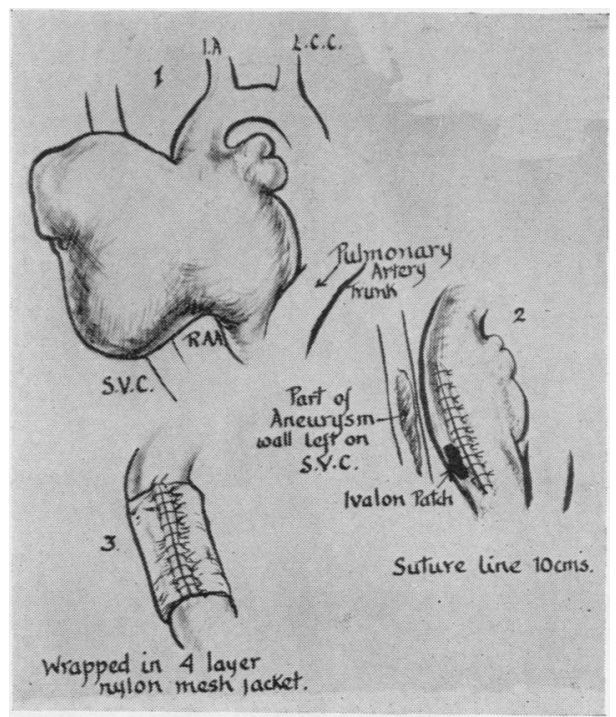

Fig. 10.-Case 3: Operation findings. 
change. The kidneys showed proteinous non-haemoglobin casts in the second convoluted and in the collecting tubules with little cellular reaction, and no glomerular or vascular lesions. The changes in the liver indicated that it had recently been exposed to a toxic agent. The renal changes were those of a lower nephron nephrosis, part of a hepato-renal syndrome, and secondary to the liver damage. The histological examination of the excised sac showed that it was for the most part $2-3 \mathrm{~mm}$. thick but with a thinned area only $1 \mathrm{~mm}$. in thickness. Microscopically the wall consisted of acellular collagen.

This disappointing result cannot be adequately explained. A prominent feature was the failure to recover satisfactory vascular tone and it seems at least possible that the prolonged hypotension in association with aortic incompetence produced a sufficiently diminished visceral circulation to make a very small dose of chlorpromazine $(25 \mathrm{mg}$.) a toxic agent for the liver. Alternatively it is possible that the liver was in some way sensitized to this drug. Perhaps hypotensive drugs should be avoided in similar cases where there is significant aortic incompetence.

CASE 4.-Mrs. M. W., aged 61, had had vague symptoms attributed to anaemia and a raised blood pressure during the previous three years. She was referred by Dr. Donald Leeming for investigation, having for six months had a persistent cough. During most of this time the sputum had been streaked with blood, without a frank haemoptysis. There was some pain anteriorly, in the lower part of the left side of the chest, and she was mildly dyspnoeic on exertion.

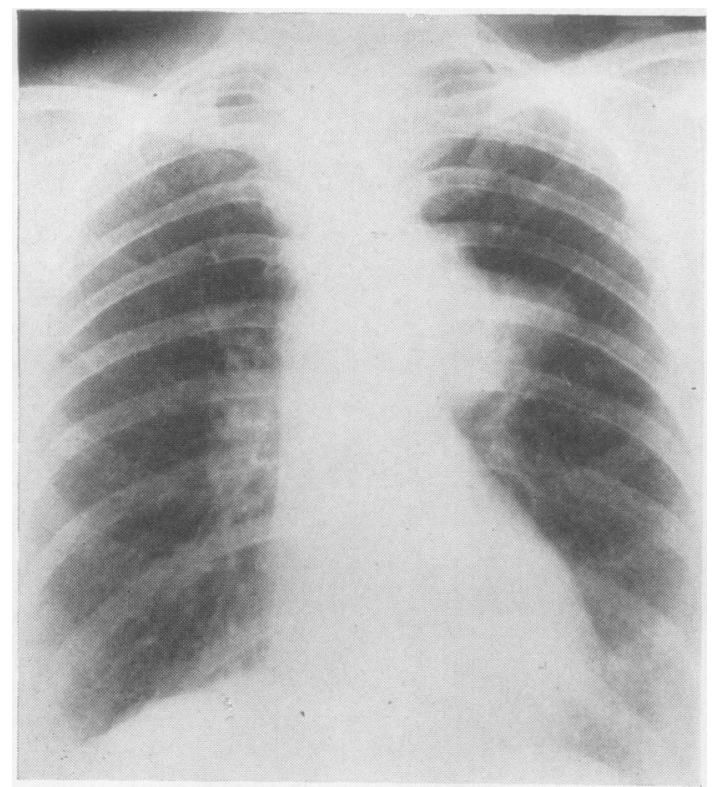

FIG. 11.-Case 4: Postero-anterior radiograph of the chest before operation.
Physical examination showed no definite abnormality, apart from a blood pressure of $240 / 120 \mathrm{~mm}$. $\mathrm{Hg}$ in the arms.

A radiograph of the chest showed a shadow on the left side which was at first thought to be a bronchial carcinoma (Figs. 11 and 12). Closer study revealed unusual calcification in the aorta, and it was impossible radiologically to separate the abnormal opacity from the aortic shadow. Bronchoscopy revealed some compression of the left lower lobe bronchus. The Wassermann and Meinicke reactions were strongly positive.

A saccular aneurysm of the descending aorta was diagnosed, and preparations were made for operation after an intensive course of penicillin. The blood pressure was reduced to $120 / 80 \mathrm{~mm}$. $\mathrm{Hg}$ after the patient had had a period of rest in bed.

At operation (B. J. B.) on September 11, 1959, a left posterolateral thoracotomy was made and a localized saccular aneurysm of the descending aorta was discovered. It was about $6 \mathrm{~cm}$. in diameter at its base, and was almost cylindrical, being somewhat longer than its diameter. It projected laterally into the upper part of the oblique fissure of the lung and was intimately adherent to the apex of the left lower lobe. The upper lobe was freed from the aneurysm without difficulty, but the lower lobe could only be separated from the sac after dividing the two branches of the pulmonary artery to the apical segment, and then dividing the lung immediately below the sac between clamps.

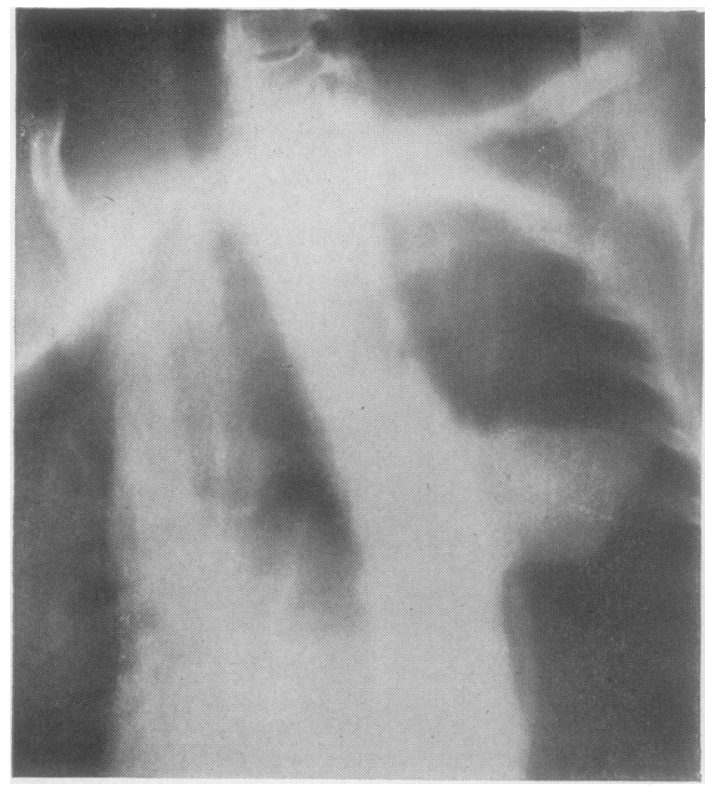

Fig. 12.-Case 4 : Oblique tomogram showing the sac of the aneurysm. 


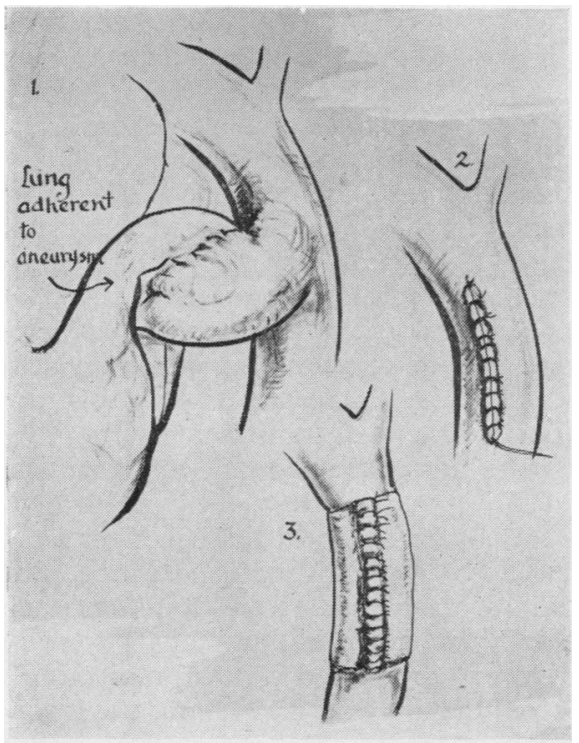

FIG. 13.-Case 4: Operation findings.

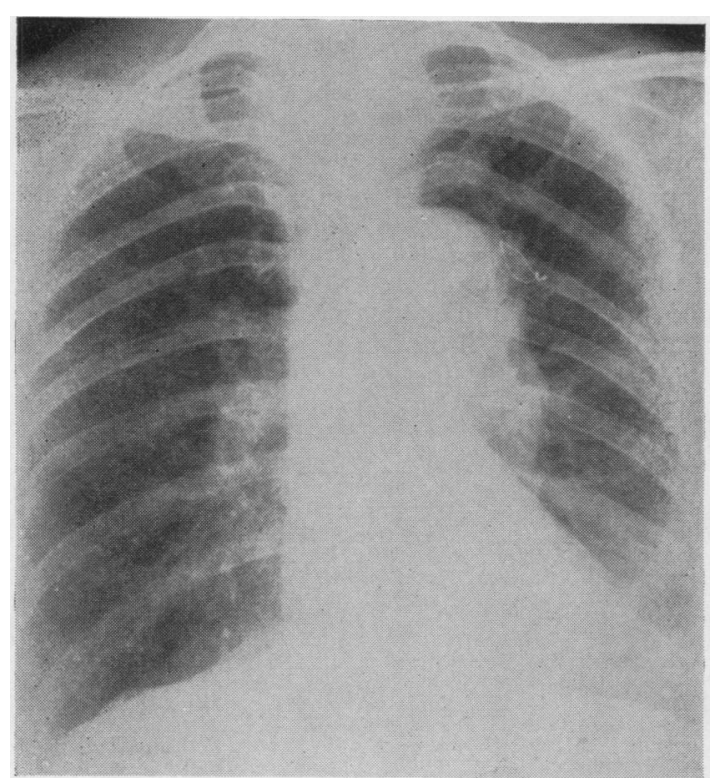

Fig. 14.-Case 4: Post-operative radiograph of the chest.

After mobilizing the aorta in the region of the aneurysm, by dividing a number of intercostal, oesophageal, and bronchial branches, the aneurysm was seen to be relatively localized, the remainder of the aorta looking healthy, though somewhat dilated.

Without interrupting the circulation the base of the sac was clamped and the sac itself was excised. After suturing with No. 2 silk, the suture line was reinforced by a double layer of nylon cloth passed around the whole circumference of the aorta over about $8 \mathrm{~cm}$. of its length. This was tightly sutured with nylon thread (Fig. 13).

Recovery was uneventful, and the patient went home on the $23 \mathrm{rd}$ post-operative day. When seen five months after operation she was continuing to make satisfactory progress. A radiograph showed some irregular opacity in the operation area, interpreted as non-vascular (Fig. 14).

Pathological Report.-The sac was filled with a thick gelatinous type of clot. Histologically the wall showed syphilitic aortitis with considerable lymphocytic "cuffing" of the vasa vasorum and a patchy infiltration of the media with lymphocytes and plasma cells.

CASE 5.-Mrs. M. D., aged 49, was a heavy smoker who complained of haemoptysis and rather persistent pain in the right pectoral region. There were no abnormal physical signs, but a radiograph of the chest showed a rounded opacity to the right of the mid-line, with a wedge-shaped projection anteriorly, which in the lateral view resembled a collapse of the anterior segment of the right upper lobe (Fig. 15). A previous "contact" radiograph in 1957 had been passed as normal. Bronchoscopy was normal, and, on the presumptive diagnosis of bronchial carcinoma, operation was advised. At operation (J. S. G.) in October, 1959, a right thoracotomy was performed. The "tumour" in the anterior mediastinum was found to be a saccular aneurysm arising from the front of the ascending aorta. It was not connected with the lung. It was mushroom-shaped, extending directly forwards to become densely adherent to the anterior chest wall. With finger dissection it was possible to get round the root of the aneurysm. The base was clamped, and sutured with interrupted No. 60 linen thread. The suture line was $4 \mathrm{~cm}$. in length. Haemostasis was

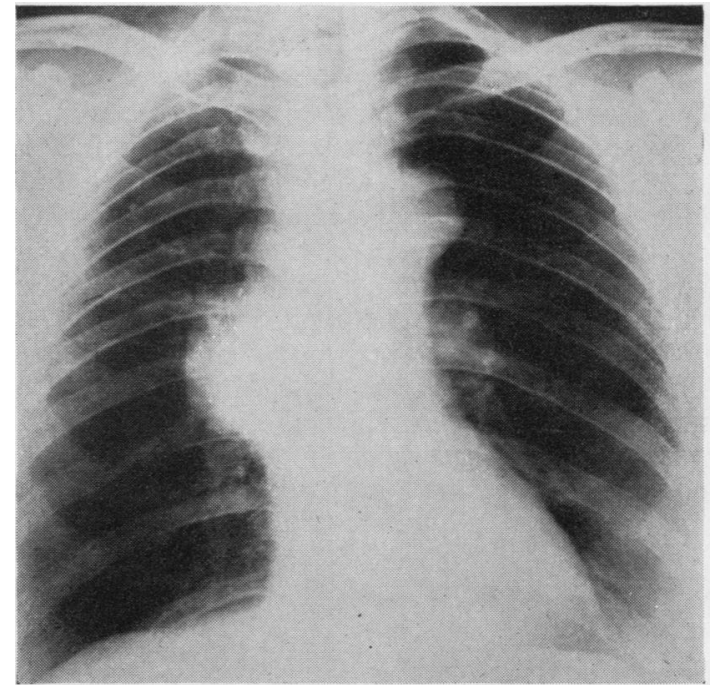

FIg. 15.-Case 5: Pre-operative radiograph of the chest. 


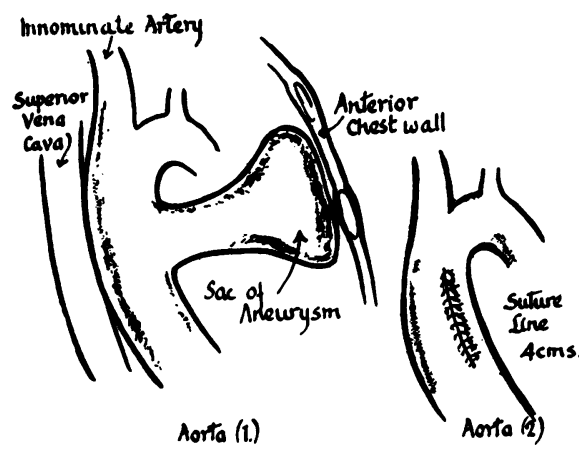

FIG. 16.-Case 5: Operation findings.

satisfactory (Fig. 16). The sac of the aneurysm was then excised, but some densely adherent periosteum and intercostal muscle had to be removed in the process. Recovery from operation was uneventful and the patient is well four months later. The Wassermann reaction was positive, and she has since been receiving anti-syphilitic treatment. The cause of the haemoptysis before operation has not been explained.

\section{Discussion}

Because of the relative rarity of aneurysms of the thoracic aorta in the British Isles our experience of the surgical treatment is limited.

On the basis of the material presented in this communication we feel that the surgical excision of saccular aneurysms of the aorta is not only feasible but reasonably safe, and that it is the treatment of choice. Previous experience with cellophane wrapping and intrasaccular wiring has been less satisfactory, and these methods seem to be unpredictable in their results.

It has been agreeable, if a little surprising, to find that the wall of the aneurysmal aorta is much thicker and tougher than that of the normal aorta. It holds stitches well, and there has been little difficulty in securing satisfactory haemostasis. On occasion calcific patches in the wall of the vessel have made the insertion of sutures awkward, but this has not been a difficulty.

We have had a certain amount of anxiety about the future in those cases (as in Cases 2 and 3 of the present series) in which the wall of the aorta was diseased. In such circumstances it was often possible to see small bulges at weak areas, and these are potentially new saccular aneurysms. The necropsy specimen in Case 3 showed several longitudinal splits in the medial coat apart from the large sac which was excised. These were more clearly seen when the aorta was opened and the wall inspected from within.

In these circumstances we have felt it reasonable to attempt to reinforce the weak aortic wall by suturing a tight jacket, or sleeve, of nylon cloth around the circumference of the vessel. This provided a good additional support for the vessel, although there is as yet no long-term evidence to indicate how the plastic material will stand up to a prolonged distending strain.

We have not attempted the complete excision of a fusiform aneurysm, but one further case which was operated on in the belief that it was a saccular aneurysm proved to have a generalized dilatation of the ascending and transverse portions of the arch, including the innominate artery. The dilatation of the aorta was reinforced with nylon cloth, but the patient died from staphylococcal infection that began as tracheo-bronchitis and later contaminated the wound.

\section{Summary}

Five cases of saccular aneurysms of the thoracic aorta are reported. The sac was excised in each, with a satisfactory recovery in four of the cases. Four of the aneurysms were syphilitic.

We should like to thank Miss Barbara Duckworth, of the Department of Surgery, University of Liverpool, who prepared the diagrams; Mr. Wilfred Lee, of the Central Medical Photographic Department, University of Liverpool, for the reproductions of radiographs; and Mr. F. Ronald Edwards for his generous help and advice.

\section{REFERENCES}

Alexander, J., and Byron, F. X. (1944). J. Amer. med. Ass., 126, 1139. Bahnson, H. T. (1953). Surg. Gynec. Obstet., 96, 383.

Bickford, B. J. (1956). Acta chir. belg., 55, 295.

Blakemore, A. H., and King, B. G. (1938). J. Amer. med. Ass., 111, 1821.

Borrie, Jorax, 5, 293.

Colt, G. H. (1925). Brit. J. Surg., 13, 109.

Cooley, D. A., and DeBakey, M.E. (1952). Ann. Surg., 135, 660.

$\overline{\text { DeBakey, M. E. (1959). J. thorac. Cardiovasc. Surg., 38, 145. }}$ and Creech, O., Jr. (1957). J. Amer. med. Ass., 163, 1439. Lin on, R. R. (1952). Angiology, 2, 485.

Meyer, A., Monod, O., Brunel, M., Nico, J.-P.. and Dubois de $\mathrm{N}$ Montreynaud, J.-M.(1948). Bull. Soc. méd. Hôp. Paris, 64, 278. Moore, C. H., and Murchison, C. (1E64). Med.-chir. Trans., 4\%, 129. W Ochsner, A. (1944). Quoted by Cooley and DeBakey (1952). Ochsner, A. (1944). Quroted by Coole

Poppe, J. K., and de Oliviera, H. R. (1946). J. thorac. Surg., 15, 186. Rénon, L. (1921). Bull. Acad. Méd. (Paris), 85, 528 .

Rob, C. G. (1954). Ann. roy. Coll. Surg. Engl., 14, 35.

Sellors, T. H. (1956). Brit. J. Surg., 43, 365.

Tuffier, T. (1902). Bull. Soc. Chir. Paris, 28, 326. 